Article

\title{
Strengthening the Call for Intentional Intergenerational Programmes towards Sustainable Futures for Children and Families
}

\author{
Czarecah Tuppil Oropilla *(D) and Elin Eriksen Ødegaard (1)
}

check for updates

Citation: Oropilla, C.T.; Ødegaard, E.E. Strengthening the Call for Intentional Intergenerational

Programmes towards Sustainable Futures for Children and Families. Sustainability 2021, 13, 5564. https:/ / doi.org/10.3390/su13105564

Academic Editors:

David González-Gómez and Sandro Serpa

Received: 22 February 2021

Accepted: 14 May 2021

Published: 17 May 2021

Publisher's Note: MDPI stays neutral with regard to jurisdictional claims in published maps and institutional affiliations.

Copyright: (c) 2021 by the authors. Licensee MDPI, Basel, Switzerland. This article is an open access article distributed under the terms and conditions of the Creative Commons Attribution (CC BY) license (https:/ / creativecommons.org/licenses/by/ $4.0 /)$.
KINDknow-Kindergarten Knowledge Centre for Systemic Research on Diversity and Sustainable Futures, Western Norway University of Applied Sciences, 5063 Bergen, Norway; Elin.Eriksen.Odegaard@hvl.no

* Correspondence: eya.oropilla@hvl.no

\begin{abstract}
As a response to the call for reimagining early childhood education for social sustainability in the future, this conceptual paper aims to suggest revisiting and strengthening the case to include intentional intergenerational engagements and programmes in kindergartens as approaches towards sustainable futures for children. In this paper, we argue that we must talk about intergenerational solidarity on all levels, including in early childhood education and care settings, and that it must be deliberate and by design. Learning from cultural-historical concepts and the UN Convention on the Rights of the Child, intergenerational programmes in early years settings are to be presented as intentional initiatives and opportunities for interrelated and collaborating actors and institutions to bring younger children and older adults together. We present a conceptual framework that features conflicts and opportunities within overlapping and congruent spaces to understand conditions for various intergenerational practices and activities in different places, and to promote intergenerational dialogues, collaborations and shared knowledge, contributing to a relational and socially sustainable future for which we aim.
\end{abstract}

Keywords: intergenerational programmes; conceptual framework; early childhood; social sustainability; cultural-historical

\section{Introduction}

Relationships between the youngest and oldest life stages have been well documented by research throughout the years, particularly within the family as an institution. Interactions between grandparents and grandchildren have long been identified as beneficial to children's growth and development. Grandparents are seen as an important family resource [1], with care and socio-educational roles [2] when engaged in play activities [3,4] and intergenerational dialogues [5]. Previous research has also established the importance of these familial intergenerational interactions as a means to pass on cultural heritage, and thus contribute to cultural sustainability [6].

However, there have been events throughout history that have contributed to changes in societies that have affected these intergenerational relations. The past couple of decades have seen an increase in mobility from rural to urban areas [7], as well as movements to other countries or continents. This internal and external migration is rooted in economic reasons as part of globalisation [8]. This diaspora led to demographic changes-the younger generations leaving to seek better job opportunities in cities and the older generations staying behind in more rural settings [9]. The diaspora also means that there are more families with young children living away from grandparents, resulting in fewer interactions between generations [10]. In most Western societies, the parent(s), who are part of what are deemed sandwich generations [11,12], need to work, while their children spend most of their time in early childhood settings, such as kindergartens or schools. Early years institutions have long been considered an arena for cultural formation [13]. They are also 
sectors that plays an important role in achieving sustainable goals [14] and contributing to building sustainable societies [15]. These institutions foster young children's formative development. As an example, the Norwegian framework plan for kindergartens [16] seeks to promote the core values of democracy, diversity and mutual respect, as well as equality, sustainable development, life skills and good health in enabling children to participate in and contribute to their communities. Engaging in social relations, exploring different aspects of interactions within a community and developing friendships is also something that kindergartens offer young children [16]. It is considered a safe and challenging space where they are given support to cope with adversity, tackle challenges and have opportunities to consider their own and others' feelings [16]. However, although children in early year settings transition and participate in other institutions within their communities, little is known about specific activities or programmes that involve children's interactions with the elderly beyond their families. There is a need for further qualitative and contextspecific intergenerational research that includes the participation and voices of the elderly and children in their early years [17].

Social sustainability concerns social, cultural and political issues that affect people's lives within and between nations [18], as well as an extension of collective rights to include future generations $[14,19]$. Hence, we argue that the attainment of social sustainability necessitates cooperation and collaboration of not just individuals but also of institutions within a particular context. Individuals and institutions with shared goals and a vision of fairness and justice for all [14] lead to outcomes of social sustainability. Further, social sustainability is also related to "finding new ways of living together, strengthening social capital and participation as well as social justice and equity" [20] (p. 342). Belonging has also been suggested as a core concept of social sustainability, as it is conceptualised as relationally negotiated and practised in kindergartens [19].

This paper aims to strengthen the call for the inclusion of intentional intergenerational programmes in early years settings, such as kindergartens. Specifically, we argue that social sustainability is a resulting outcome of intergenerational programmes in kindergartens, making a case for it to be included in planned activities. There is a growing body of intergenerational research that documents intergenerational programmes among different ages and in different settings [17], and early childhood education and care is an emerging field in this scientific movement. In this paper, we acknowledge current intergenerational work being undertaken in early childhood education and care settings, but argue that aiming for sustainable futures requires more intentional and deliberate conceptualisations. To support our argument, we present our first attempt at a macro conceptual visual representation of elements of intergenerational programmes in kindergartens. A macro view allows us to theorise conceptualisations and components of conditions for intergenerational engagements and programmes in kindergartens. As part of a project in KINDknow-Kindergarten Knowledge Centre for Systemic Research on Diversity and Sustainable Futures, we write from a position of belief in the potential benefits and outcomes that intergenerational engagements offer to families and institutions, children and older adults, as documented by previous literature $[3,5,21,22]$. It is our intention to thrust forward intergenerational engagements and programmes within the field of early childhood to create bigger spaces and opportunities for dialogues, play and collaborative explorations between young children and older adults in early childhood settings. Through this conceptual work, we offer a framework for understanding and analysing ongoing intergenerational engagements and programmes in early childhood institutions. This framework will also be used for the analysis of data generated in the larger research project to which this paper belongs. In that research project, which aims to explore and understand conditions for intergenerational engagements during a pandemic, data were generated in Norway and, incidentally, the Philippines. As such, this conceptual work reflects the need for localised interpretations.

Before we move forward with the discussion, we offer some operational definitions for clarity. In this paper, generations pertain to relational cohorts arranged in a structural system of social ordering circumscribed in particular social locations with material, social and 
cultural processes in which people act and participate in ongoing social life as individual and collective actors [23]. In particular, we focus on intergenerational engagements of young children in the early years stage from birth to six years of age, and older adults 50 years old and above to include persons who have become grandparents at earlier stages of life. Early childhood institutions refer to societal organisations in which young children participate, and where intentional, relational and glocal intergenerational engagements and programmes happen. This includes both family and early childhood education and care settings. Kindergartens are used concurrently and alternatively with early childhood education and care (ECEC) settings or early years settings and refer to the same meaning. Intergenerational engagements refer to more informal but intentional interactions among different generations. As above, our focus is on engagements between younger children and older adults. These engagements happen in family and community settings, as well as in institutions. Intergenerational engagements could be considered an umbrella under which intergenerational programmes belong. This terminology is used concurrently and alternatively with intergenerational interactions. Intergenerational programmes refer to more formal intentional initiatives bringing younger and older generations together within and across institutions through practices and activities. Characteristics of intergenerational programmes, particularly those involving children in early childhood years, will be expounded within this article. Sustainable futures refer to a vision of a desirable future of a culturally, socially, economically and ecologically balanced way of living that is directly influenced by present and past initiatives. In this research, activities, practices and programmes that promote intergenerational solidarity are proposed to attain this vision.

The next section discusses the theoretical underpinnings of this conceptual work. This is followed by a section that presents the macro-visual conceptual framework, which is later broken down and discussed in smaller parts. We conclude the paper with a discussion of the implications and limitations of the conceptual framework.

\section{Grounding Theories for Conceptual Development}

\subsection{Conceptual Process}

To understand how intergenerational programmes in kindergarten can contribute to social sustainability, there is a need to elaborate on the different components, elements and concepts that contribute to the conditions affecting these programmes. In this paper, we present a framework for understanding and analysing these elements and concepts through a visual graphic representation. Each concept is represented and discussed individually and visually regarding other elements in the framework.

Our conceptual process began as we tried to utilise existing visual models, such as Hedegaard's Cultural-Historical Wholeness, e.g., [24,25] model and Bronfenbrenner's Bioecological Model of Human Development $[26,27]$, to represent how we understand and view intergenerational engagements and programmes. However, there were limitations to the existing models. We needed a model that captured and highlighted the interactions of each element. We also needed a visual model to capture time and artefacts, which have implications for understanding intergenerational engagements and programmes. Our inquiry began with a review of the literature within the field of ECEC and social sciences. In this paper, we present our preliminary conceptualisation, which could benefit from further development through a more extensive and systematic literature review.

In the succeeding part of this section, we discuss the grounding theories that have influenced our conceptual process.

\subsection{Cultural-Historical Perspectives}

This conceptual work draws on cultural-historical philosophies and theoretical perspectives. Common to these epistemologies is the view that humans live their lives, entwined in both global mechanisms and local activity settings, and are to a large extent dependent on cultural-historical traditions and institutional dynamics of personal relations and how families, practitioners and children interact with artefacts and material conditions. 
These cultural-historical traditions and mechanisms, which are continuously renewed in social activity, are considered central forms of life, constituting life trajectories [24,28-30]. Vygotsky's [31] recognition of social processes and interactions as major factors leading to development in human beings of all generations may be young children or older adults. Dealing with the problems of becoming human is central to cultural-historical approaches. As pointed out in the prologues of Vygotsky's collective works [32], Vygotsky believed that higher psychological phenomena are stimulated and constituted by social relations. His ideas were influenced by the stage director Stanislavski, whom he cites, and also by the philosopher Bakhtin [33]. These authors give attention to imagination, emotion memory, communication and dialogue, and were elaborated in Vygotsky's work [32]. Throughout his works, Vygotsky dealt with the classic problems of psychology: perception, memory, thought, emotion, imagination and will, all through the lens of human development in societal systems. Social interactions and people's interactions with materials and artefacts in activities are a major factor leading to social and cultural development and growth [31]. For Vygotsky, becoming human implies a mental picture of human processes becoming ordered, systematic or controlled through interaction (e.g., speech starts externally and ends as inner speech; emotions move inward and escape peripheral control; imagination is play gone inwards) [32].

In several contexts, Vygotsky discussed the emergence of indicative gestures in the infant's interaction with an adult [34]. He points to the experience that, when an infant cries or reaches out for an object, the adult attributes meaning to the act. Even if the infant has no particular intent, the act will function as communication. The adult will respond accordingly to the needs of the children as they understand them. In this way, the adult's attempt to interact with the child will include the child in a social activity before the child has the capacity or understanding to respond adequately in the interaction. Vygotsky argued that that this secures a foundation for the cultural transformation of the infants' actions into intentional indicative gestures, talk and activity [35].

This observation and discussion were further theorised in Vygotsky's work on the Zone of Proximal Development (ZPD) [31]. The idea in ZPD attends to the role of dialogue and interaction as precursors to inner speech. When an expert interacts with someone less expert, the latter is able to reflect on the dialogue and interaction, to use distinctions in concepts, pick up details in actions in activities, reformulate thoughts and change actions. In Vygotsky, we see the adult implicit as the expert (e.g., teacher, parent, more knowledgeable peer), and the child is implied as the less expert and the learner. In our study, we anticipate that children are experts in certain areas (e.g., experts in their own emotions and imaginations and in certain modes of action). We thereby challenge an automatic assumption of the generational order [23] of adults, older or younger, automatically being more skilled in every respect than children.

Vygotsky also discussed the problem of age and the role of crises in critical periods of life [36]. He states that age is an objective category and not an arbitrary, freely chosen, fictive value. Nevertheless, he problematises the theories that periodically scheme age groups because they tend to isolate an objective trait. For this reason, he argued that guideposts that mark age must see child development as a complex process that cannot be determined completely according to one trait alone at any stage. In different children, critical periods will occur differently, even if being born and developing and losing teeth can be seen as a biological and general crisis in childhood years. During the passage of a crisis, even in children most alike in type of development and in social situations, there is great variation and, therefore, a predefined crisis should be considered the exception rather than the rule in child development. For Vygotsky [31], the concept of crisis suggests a lifelong process, and hence suggests the need for a relational, interactional and interdisciplinary understanding of concepts. Later pioneering scholars in the fields of early years' child development and growth, such as Barbara Rogoff and Mariane Hedegaard, have further developed this problematisation and provided empirical research to show that diverse human cultures assign different roles and expectations to children of the same age [37]. 
Barbara Rogoff and her team described learning processes in diverse cultural settings. Studying indigenous communities, they conceptualised intergenerational learning as Learning by Observing and Pitching In (LOPI) [38]. Central to LOPI is that the child (articulated as the learner) is incorporated and contributes to the family's endeavours. Communication will be both nonverbal and verbal, and the learner will be eager to participate and belong. The social organisation of activities will be flexible and collaborative. Additionally, there will be a blending of ideas and agendas. Rogoff and her team found that, in the same communities, children from the formerly indigenous community were likelier than children from the cosmopolitan community to show aspects of LOPI. Children showed wide and keen attention to surrounding events and used a balance of articulate nonverbal conversation with talk. The study of participation in cultural practices does not categorise people by a single ethnicity, race or nationality, and makes generic assumptions about their cultural ways based on their "social address"; it focuses on examining what people $d o$. Rogoff argued that the histories of LOPI practices across generations and locales are an important tool for understanding commonalities and differences that may occur across different times and places [39].

\subsection{Cultural Artefacts}

Central to human perception and formation are interactions with the cultural artefacts (tools) made available to us. Humans experience and understand the world in terms of the artefacts of our culture, and these can be considered key to the development of what Vygotsky [40] referred to as higher mental functions, such as remembering, imagining and understanding symbols, signs and conceptions. Max Wartofsky questioned the notion that human perception is natural, and argued that it is an activity that is mediated by artefacts such as tools, language and models [41]. These mediating artefacts, Wartofsky argued, are objectifications of human needs and intentions "already invested with cognitive and affective content" [42] (pp. 205-206). Activities involve multimodal processes and multiple forms of awareness. Wartofsky categorised artefacts into three forms of perceptual and performative activities, as follows:

(1) Primary artefacts: traditionally a hammer, a needle, scissors or a camera; used in production and labour.

(2) Secondary artefacts: relating to primary artefacts (such as a user manual for a camera or instructions for cooking (a recipe).

(3) Tertiary artefacts: representations of secondary artefacts, symbols, theories and models (imagining new ideas).

The process of gradually taking over and being able to use an artefact is referred to as appropriation by Barbara Rogoff [28]. Relevant to our study is that an artefact, whether a manual tool, a sign, a model of thinking or language, or all these at the same time, will entail a history and come with connotations and rules of use, and can bring up feelings and create memories. A scenario can serve as an example; when an older adult, in a programme of intergenerational meetings, will meet children, this activity can trigger their own childhood memories and actualise, for the older adult, the use of certain artefacts and their own experiences with mastering the use of a tool, and will easily set a standard for how to use the tool, when to use it and whether it will be appropriate in certain situations. For the child, the availability of certain artefacts for use in activities will evolve as experiences in the situation, and will later be a resource in the embodied memory of concepts for use, modes of action and emotions triggered.

Wartofsky wrote about the tertiary artefact as a representation of "imaginative practice" [42] (p. 207). This inspired Michael Cole [43] to exemplify how a certain pedagogical approach can be a tertiary artefact in this regard, explaining that the tertiary artefact can be embodied as alternative canons of representation. Once an imagination of an idea can be lived perceptually, it can also come to influence and change our perception of the actual world. As such, tertiary artefacts enable perception, planning and revising of practice [43]. This category will serve as a thinking tool for further theorising in this paper. 
The concept of artefacts allows us to problematise age, understood as a historical and biological chronological process only, and intergenerational activities and programmes. As much as chronological age is not the only clue to biological ageing, nor will artefacts mean the same for people in and across a certain age group. There might be collective memories because a certain version of an artefact was stable in a certain time and, for that reason, many of the same generation will have similar experiences. For example, the telephone as an artefact has certain characteristic aesthetics and use in historical time and culture; nevertheless, as an artefact, it indicates a use and meaning that could work across generations. An artefact, whether a manual tool, a sign, a model of thinking or language, or all these at the same time, will entail a history and come with connotations and rules of use and can bring up feelings [44].

\subsection{Cultural-Historical Wholeness Approach-Visual Model}

The proposed conceptual framework also leans on Hedegaard's cultural-historical wholeness approach [45], where a social situation of development occurs in an activity setting at a particular time laden with motives and demands, resulting in crises and/or development within institutional practices. Mariane Hedegaard is located within a culturalhistorical approach to learning and development, where she has explored ideas in a dynamic relationship with other researchers. First and foremost, she is inspired by Vygotsky and the Russian cultural-historical legacy. In her work, Hedegaard also used arguments from authors within Childhood Studies. These perspectives allow her to study contemporary society and the way society organises and conditions the lives of children and families. Central to her theorisation is the recognition of the lives of the contemporary child living across cultural trajectories, such as families and institutions (e.g., kindergartens). She argued that children and families must be studied in a localised time and space to take individual variability and contexts into consideration [46,47]. Hedegaard's major contribution has been to show how institutional practices, such as family life, day care (kindergarten) and school, mediate societal priorities. The wholeness approach allows us to analyse historically accumulated institutional practices.

Hedegaard visualised her thinking with a model for analysis that considered three perspectives: individual, institutional and societal [24,48]. With this model, she explained a wholeness approach, with an emphasis on visualising how children may participate in several institutional settings, such as home and kindergarten (see Figure 1). We have taken these three perspectives, as well as her emphasis on the variety of different institutions and demands in which a child can move in-between. Moreover, we recognise her work on motives, demands and conflicts that will be played out in different activity settings and processes.

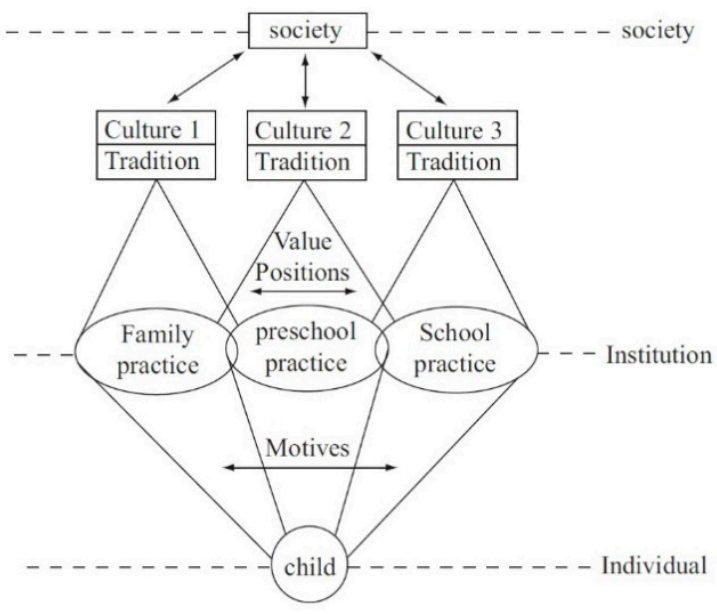

Figure 1. Hedegaard's cultural-historical wholeness visual model. Reprinted with permission from Mariane Hedegaard (2008). Copyright 2008 Mariane Hedegaard. 
Hedegaard also revisits Vygotsky's concept of crisis in child development [25], a concept helpful in understanding inevitable events in human life connected to time and development. Crises arise as conflictual relations between a child's motives and the social situation of the child. Hedegaard argues that new developmental periods come to life through children's experiences of conflicting intentions, leading to crises. She mentions that a crisis may be noticed when an infant starts to walk. With the new bodily skills, a child becomes able to move independently. Consequently, new demands are put on the child's caregiver(s) for the child's safety and for the unpredictability of what can happen when the child can explore the world with its artefacts and local places. When the child becomes more skilful, both the caregiver(s) and the child may enter into a conflict between obeying the caregiver(s) and allowing the child to explore the environment. Related to our effort to strengthen intentional intergenerational programmes towards a more sustainable future, the concept of crisis can open up understandings of how everyday life crises put necessary demands and conflicts into play, which could, if dealt with in sound ways, build resilience and growth in both child and caregiver(s). We anticipate that intergenerational programmes and practices have the potential to build resilience and growth because more life experience, knowledge and skills can come into play. These knowledge and skills of different generations will vary and can broaden and offer resources to activities, as well as bring new demands and conflicts to the situation, so new moments of learning can take place.

We have also taken these into consideration in our conceptualisation by recognising that intergenerational practices, programmes and processes will have contextual and historical connotations because artefacts can carry meanings and history, and that time is a continuum that generations continuously journey on. Intergenerationality necessitates a consideration of the events of the past, present and the future. There should be an acknowledgement that, while time is continuous and never-ending, it is fleeting and temporary. Intergenerational thinking should always consider the changes that time brings. One such instance is the transitory nature of age, as also pointed out by Vygotsky [36]. Thus, history and time are at the core of our conceptual work. Including these perspectives allows for a critical examination of assumptions surrounding intergenerational programmes in the context of specific historical and cultural settings and institutional practices, as well as the dynamic roles and positions of all actors within the system.

\subsection{Childhood Studies and Glocal Understandings}

Our conceptualisation also subscribes to the theoretical underpinnings of the UN Convention of the Rights of the Child (UNCRC) [49], which is one of the guiding forces of concepts in the new sociologies of childhood, also referred to as Childhood Studies, as well as implemented in most frameworks and guidelines for early childhood settings around the world, including the Norwegian framework plan for kindergartens [16]. Using the UNCRC foregrounds a consideration of uncertainties and paradoxes in identifying the best interests of children [50].

Childhood Studies is a field of study that examines contemporary and global challenges and issues concerning "the child", "children" and "childhood". Children's competencies, agency, voices and rights are central to this field. The field is critical of the normative view of children, childhood and human life stages, where children are viewed as human "becomings", which connotes an incompleteness and instability that is attained in adulthood [51]. Theorisations of children as both human "beings" and "becomings" [52] emerged from Childhood Studies that emphasise both childhood and adulthood as temporal life stages that are subject to changes over time and are both fundamentally unstable and incomplete.

While this may put our conceptualisation in the middle of seemingly opposing ontologies, where Childhood Studies argues for more localised study of children to see the variability of individual context [53-56] and Cultural-Historical perspectives [31] are considered part of the "grand theories of child development" [46] due to a more generalised 
and standardised view of the development of children, we will reiterate the need for interdisciplinary understandings in this conceptualisation of intergenerational programmes, as it goes beyond children's development and touches on institutional and societal conditions in place.

Rather than seeing developmental psychology, sociology and anthropology as opposing fields, our conceptualisation subscribes to the concept of 'glocalisation' - that is, an understanding of both global and local conditions and considerations [57]. Ødegaard [57] has made a strong case for a glocal view, which she applied to teachers and early childhood programmes, whereby globalisation does not necessarily penetrate every aspect of the local culture, local traditions and views in the development of models and programmes. She writes that, "in spite of globalisation, local conditions can be adopted, held on to and transformed. Local models and varieties across a nation can also put pressure on the development of local models" [57] (p. 44). As such, the glocal view of intergenerational programmes demands both global and local awareness, knowledge and perspectives that necessitate a localised study to see the variability of individual contexts alongside grander and more macro views offered by grand theories of child development. An example of these local particularities are terminologies used. While global research indicates that "older adults" is a more respectful terminology to refer to members of the older generation ages 50 years and above [58-60], this terminology causes confusion in Norway, where the terminology "elderly" is acceptable and more widely used. Another example particular to the Norwegian context is the preference to use "generasjonsmøter", which means generations meeting up and being together to engage in dialogues and shared experiences, instead of the term "intergenerational programmes", as the former carries a more culturally nuanced understanding and meaning. In this light, this conceptual visual representation is not static and can be adjusted to have fewer or more elements in play, using culturally appropriate terminologies specific to local settings, countries or contexts, which could be realised as data are generated. This makes space for applicability to other contexts and countries and, as such, for future research in both Western and non-Western studies. For the purposes of this paper, however, the term "elderly" is used concurrently and alternatively with "older adults", and "intergenerational programmes" are used to cater to broader audiences.

\subsection{Characterisations of Intergenerational Programmes in the Field of Early Childhood Education and Care (ECEC)}

Before we present our conceptualisation, there is a need to discuss what intergenerational programmes are and the history behind them. Intergenerational programmes came about as a response to several societal factors that affected the lives of children and adults, resulting in changes in demographic trends, family structures and residential arrangements that have been observed by various societies in the past few decades [61]. These changes, in part due to globalisation efforts and economic pressures, have led to societal inequalities that are still seen to this day. Migration, both internal and external, has economic roots and is considered both a symbol of inequality and of the growth and development of cities and urban areas [8]. The diaspora of people from rural to urban areas, as well as within and across countries due to industrialisation and urbanization, has been a global phenomenon that has created both opportunities and societal difficulties that need to be addressed. The diaspora has led many families to migrate from their hometowns to places where there are available jobs, resulting in generations frequently becoming distanced or segregated from one another, particularly younger and older people.

Additionally, we now have better technologies for communicating and sharing information with one another, as well as for caring for each other. Due to improved medical technologies and better access to social aid and medical care, the elderly are living longer in most countries $[21,62,63]$, but not necessarily living better, as reports of social isolation and loneliness in the elderly population increase [61]. In fact, due to societal changes, older adults have less contact with young children in many countries because older adults live in old peoples' homes and many young children spend most of their time in day care 
centres, pre-schools and schools [6]. These societal trends, coupled with an increase in age-segregated communities and a decrease in intergenerational exchange, created the need for the development of intergenerational programmes.

Intergenerational programmes are systemic efforts to bring different generations together. They can be understood as activities or programmes driven by institutional policies that increase cooperation, interaction or exchange between or among different life-stage cohorts. They involve the sharing of skills, knowledge or experience to promote mutual benefits and foster relationships. Further, these programmes are conceptualised with aims to meet the needs of both populations by fostering growth, understanding and friendship between generations, and they are enacted within the best interests of both populations who are considered more vulnerable and dependent on society: young children and the elderly.

Over the past few decades, a growing body of literature has described the growing age separation within societies [64]. Although older adults live longer, they are more prone to being socially isolated [65]. Younger children in some countries have been found to have little opportunity to interact with older adults [6]. This pattern of increasing age segregation has been linked to a decline in life satisfaction among older persons, and an increase in negative stereotypes towards the aged and ageing among younger people. As the Together Old and Young (TOY) Consortium found:

"In the Western world, children live in a separate world from older people. Apart from family members, they do not come into contact with older people. Therefore, this is a way of bringing them into contact with older people, other than grandparents. For older people, it brings something new, brings life to them."-Leila, coordinator, "The Dice: young meet old", the Netherlands [6] (p. 3).

Intergenerational programmes have three main criteria: (1) they involve more than one generation; (2) they are planned on purpose for progressive, mutually beneficial learning; and (3) they promote greater understanding and respect between generations and, consequently, they create community cohesion $[6,66]$.

In the field of ECEC, intergenerational engagements and programmes are intentional systemic initiatives to bring younger children and older adults together within and across institutions through practices and activities that promote the learning and development of all involved [66,67]. These initiatives aim to bring together practitioners, academics and policy makers to create purposeful, intentional and continuing exchange of learning and resources between older and younger generations [64]. This characterisation situates intergenerational engagements and programmes in social, cultural and historical settings with traditions, values and norms, wherein actors participate with different motives and positions of power within activities and practices, and with the use of cultural artefacts or tools. Intergenerational programmes can also be characterised as opportunities for children and adults to develop through social interactions with different people in different institutions through different practices and activities. In doing so, children and adults are given a venue to appropriate new competencies, motives and intentions by being faced with possible crises of transition and transformation. Research studies acknowledge the benefits of having intergenerational activities $[3,21,22,68]$. It has been found that all parties who take part in intergenerational activities may gain a lot from them. EuroChild [69] listed some of the benefits that young children, senior citizens and the community gain from intergenerational activities. These include young children learning about community traditions, local history and values, and the elderly feeling more valued and useful to society. There is also improvement in mental and physical health, as well as a reduction in fears and prejudices within society. Intergenerational programmes can also contribute to efforts towards healthy, safe and age-friendly societies to combat increasing loneliness and social isolation. In this, governments play a vital role in developing opportunities for generational meetings in various gathering places [70]. 
In the next section, we present our conceptual model of intentional intergenerational programmes that involve early childhood institutions. We have used these characterisations of intergenerational programmes in our conceptualisation.

\section{A Visual Representation of Elements of Intergenerational Programmes in Kindergartens}

In this section, we elaborate on our conceptual framework by presenting it in full macro view and later breaking it down per element.

Figure 2 illustrates a full diagram of the conceptual visual representation, which includes different interacting elements of intergenerational programmes in kindergartens. Each element is considered a concept in its own right-that is, if taken as an individual unit, it could function differently in relation to other elements in different settings and contexts. These elements and their relationships are elaborated on in the succeeding section of the paper.

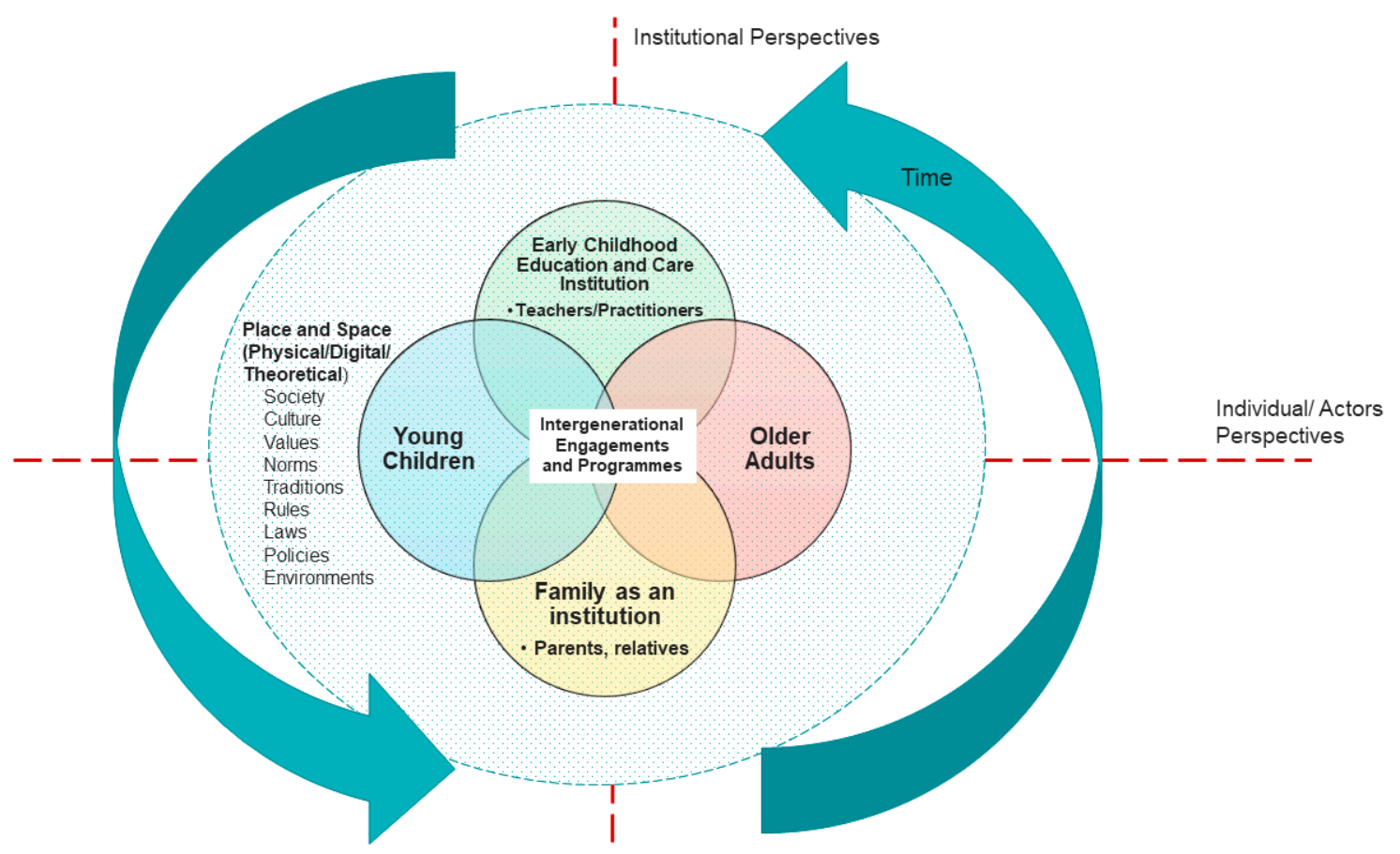

Figure 2. Conceptualisation of intergenerational programmes in kindergartens.

As previously discussed, this conceptualisation took inspiration from Mariane Hedegaard's [24,71] model, where three perspectives are present-individual, institutional and societal. These three perspectives are present in this conceptualisation. The first two interacting elements lying on the $x$ axis, represented by the red horizontal broken line, make up the individual/actor perspectives. The two interacting elements lying on the $y$ axis, represented by the red vertical broken line, include institutional perspectives. The societal perspective is represented by a dotted circle outside the four overlapping circles of the elements. Small dots penetrate the overlapping circles to visually represent the implications this has for the other elements.

In this visual representation, the interactions and relations of each conceptual element in play are highlighted. Venn circles provide a fitting visualisation of the elements and their relations and interactions, as the congruent or conflicting overlaps of these conceptual elements that we propose are the spaces where social sustainability occurs. The overlapping and intersecting spaces are the sites where dialectical processes of crisis/conflicts of conditions and demands among the different elements happen, and hence should be considered spaces for opportunities for learning, development and collaborations. As previously mentioned, this conceptual framework can have more or less interacting Venn 
circles representing other generations/age-cohorts and institutions to fit specific contexts and communities. For the purposes of this preliminary presentation, our focus will be on representing interactions that involve the youngest and oldest generations in early childhood institutions.

\subsection{Individual Perspectives: Young Children and Older Adults}

To understand intergenerational programmes in kindergartens and highlight social sustainability as one of the outcomes, interactions between younger children and older adults is vital. As such, these are the first two elements in the conceptual visual representation - two separate yet interacting individual/actor perspectives, characterised by two overlapping Venn circles. The blue circle represents young children, while the red circle represents older adults (see Figure 3).

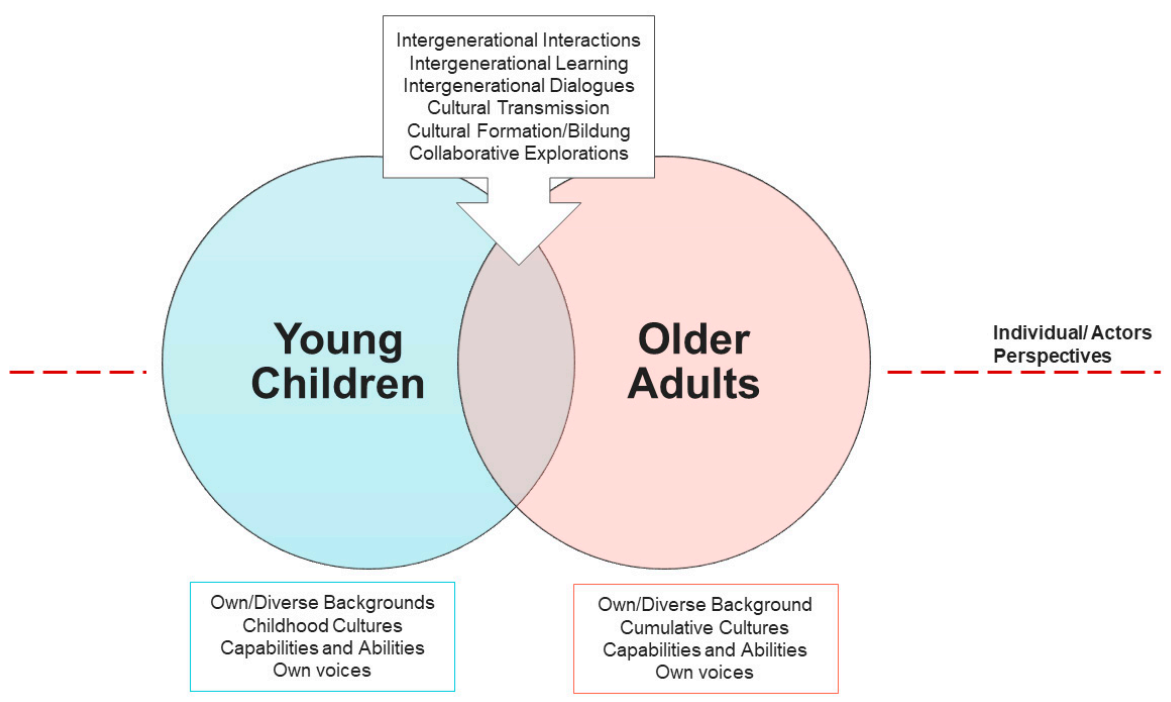

Figure 3. Individual perspectives: younger children and older adults.

In this conceptualisation, the plurality and diversity of backgrounds, cumulative cultures and experiences accumulated throughout their years and unique voices are acknowledged. Both age groups have their own unique cultures from which the other age group could benefit, and both age groups seek empowerment from their positions as dependents of society [6]. On the other hand, both young children and older adults are viewed in a socio-cultural context, where they prosper and make meaning through interactions with their environment and each other [72]. As such, they are viewed as active social agents who participate in knowledge construction and the daily experiences of childhood [23,73-77].

Additionally, this conceptualisation views children and older adults as both beings and becomings, subscribing to the argument that both children and adults experience unstable lives that are subject to change over time [52]. The temporality of time is central to the view that "perceiving children as 'being and becoming' does not decrease children's agency, but increases it, as the onus of their agency is in both the present and future" [52] (p. 311). As such, young children are deemed capable and active authors of their own narratives and lived experiences [76], as they participate in activities in different institutions. As such, this conceptualisation highlights young children's ability to voice their thoughts and participate in matters that involve them [49], and it takes into account their perspectives and participation within activity systems and institutions [24].

Congruently, this conceptualisation recognises older adults' wisdom and strengths in that they could contribute to society, most especially to younger children. At this point, it is noteworthy that, in this conceptualisation, the terminology "older adults" denotes people who are 50 years old and above. This age group stratification is preferred because it is more inclusive of people who have become grandparents in their younger senior years. 
The overlap of the Venn circles in Figure 3 is a representation of young children's and older adults' relational and interactional relationships. This visualisation supports Alanen's [23,77] view of intergenerationality-beyond seeing generations as a system of structure categorised by age, intergenerationality necessarily entails a relational view of generations.

The intersection in the middle represents a space for intergenerational interactions, learning and cultural transmission between actors. While it can also be a space where individual views, voices and differences collide and conflict, it is an opportunity for dialogues between actors or agents to share their own knowledge about the world-older adults about their experiences with food, animals, navigating landscapes, etc., and younger children as experts in navigating digital tools, being more native to digital spaces than some older adults. As such, this is an opportunity for generations to impart their knowledge to each other, creating a community and cycle of lifelong learners and lifelong learning with shared knowledge that could be sustained for years to come. Succinctly, this contributes to the tenets of social sustainability.

\subsection{Institutional Perspectives: ECEC Institutions and the Family}

The next intergenerational elements under consideration are institutional perspectives, represented by another set of interacting Venn circles lying vertically on the y axis (see Figure 4). In this representation, the green circle represents ECEC institutions that may be known in more culturally appropriate terminologies in specific contexts (i.e., kindergartens or barnehager in Norway; preschool or nursery in the Philippines). The yellow circle represents the family as an institution. It is within these institutions that children in their early years and older adults participate the most in their everyday lives. These institutions are the sites that provide opportunities for young children's and older adults' voices to be heard and for their actions to be recognised, and these institutions are spaces and places where they belong and are included. This conceptualisation situates cooperation actors, such as early years practitioners and parents, in these institutions, an interaction that is most often referred to as home-school partnerships. Other institutions can be included in the representation, such as elderly care institutions but, for the purposes of this paper, only early childhood institutions and families are included.

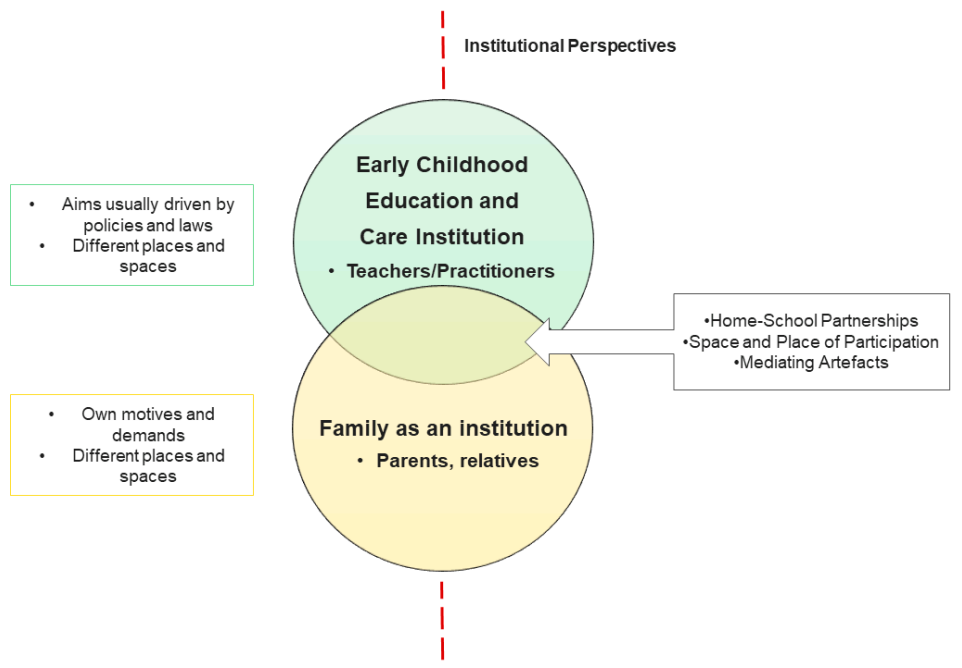

Figure 4. Institutional perspectives: kindergartens and families.

Family institutions and early childhood institutions, located in specific physical places, have specific motives and demands that they aim to address and fulfil under specific policies and laws through different activities and practices. Activities and social situations within and across early childhood institutional settings and present learning and development through participation in institutional practice and across different institutions (i.e., 
kindergartens, families, etc.) [71]. These activities are guided by cultural and historical practices and traditions, and are most times mediated by cultural artefacts. In addition, as these institutions are widely considered part of communities, Barbara Rogoff's [28] guided participation in community settings is also relevant, where human development is a cultural process involving participation in institutional or community practices and traditions [28].

\subsection{Societal Perspectives: Physical, Digital and Theoretical Places and Spaces}

As has already been mentioned, physical, digital and theoretical places and spacescollectively referred to as societal perspectives-also need to be represented. Their components include cultures, values, norms, traditions, rules, laws, policies and physical environments, as well as global discourses in which intergenerational programmes are situated. This is represented by a big dotted outer circle that penetrates the Venn circles nestled within it to visually represent its implications or influence on the other elements (see Figure 5).

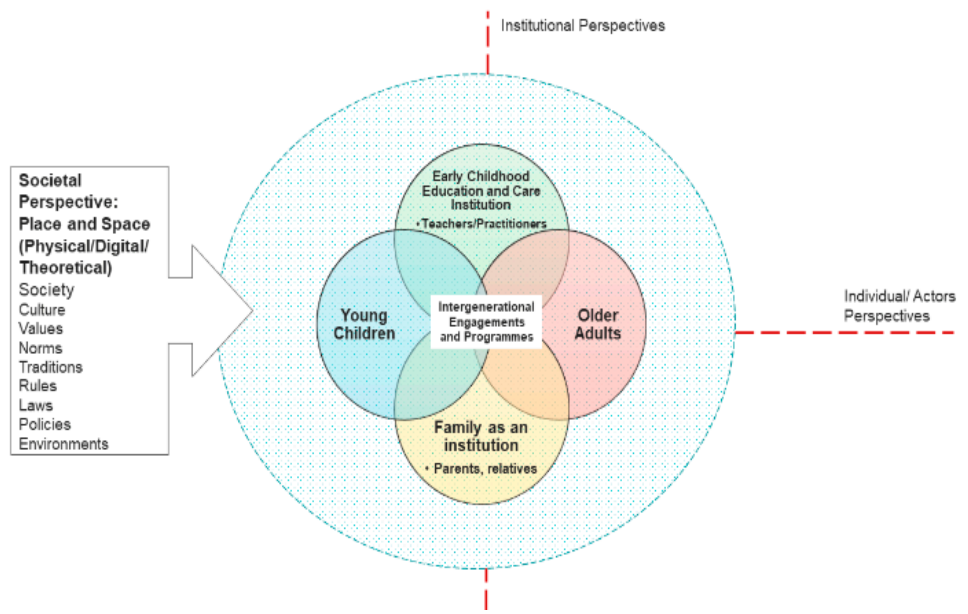

Figure 5. Societal perspectives: physical, digital and theoretical places and spaces.

In this conceptualisation, places and spaces are used concurrently. However, the main difference lies in places being physically bound by a certain location, whereas spaces can take up a more abstract location. This conceptualisation subscribes to Harrison and Dourish's principle that "space is the opportunity; place is the understood reality" [78] (p. 67). In their paper, Harrison and Dourish discuss the intricacies of these two concepts and how difficult it is to differentiate them from each other. They write that a place is a space where behaviours are formed and enacted within a specific and contextualised set of cultural understandings and norms [78]. They have argued that everything in this world is located in a space that is tied up to a specific place; hence, both have implications to designs [78]. Consequently, we understand physical places in terms of specific geographical locations with corresponding cultures, norms and values. Linked with these places are the rules, policies and guidelines governing programmes and activities within these locations. Therefore, the role of governments and good governance are considered vital in understanding intergenerational programmes in early childhood settings.

The concept of space is broader. Harrison and Dourish [78] offered a definition of space as "the structure of the world; the three-dimensional environment in which objects and events occur, and in which they have relative position and direction" (p. 68). Space has also been used as a metaphor in computing, media and virtual platforms, which presents opportunities for collaborations and connections. As such, in this conceptualisation, digital spaces are included in the recognition of shifting social topologies mediated by digital tools that enable intergenerational interactions in "cyberspace". Technological advances make it easier for young children to gather and share information. In a generation known as 
the interactive information age, children are more exposed to technological tools such as the computer, internet, mobile smartphones and tablets that enable them to gather more information and communicate faster. In the EU Kids Online [79] research project final report, the authors found that more children are using the internet and younger children are getting online. These findings characterise young children as digital natives and pose both opportunities and benefits as well as potential risks. Nowadays, some early childhood settings have included the use of digital technologies such as tablets and smartboards within the guidelines of their national early childhood curricula. Becoming responsible for digital citizens navigating this space is vital and, as contemporary parents and practitioners seem to see value in allowing their young children to use digital technologies, there is a need for adults to further build up their own digital social skills [80], making it a shared space for learning and development.

In terms of theoretical spaces, intergenerational programmes could be situated within scientific fields that may form the basis of how activities and practices are to be implemented. One such example would be the employment of the tenets of the UN Convention on the Rights of the Child [49], which always require that children's rights be upheld as intergenerational programmes are planned and implemented. Ratified by most nations, the UNCRC has 54 guiding articles that could be categorised into four groups-survival, development, protection and participation. The UNCRC espouses the view of children as competent, strong, active, participatory, meaning-makers and fellow citizens, and is the guiding force behind rights-based participation. Children's participation could be practised and realised in the family, in alternative care, in healthcare, in education, in play, recreation, sport and cultural activities, in the media, in the workplace, in judicial proceedings and in situations of violence, as long as the basic requirements for effective and ethical participation, as prescribed by the Committee on the Rights of the Child, are actively acknowledged and followed [81].

\subsection{Time}

Another element that needs to be considered in the understanding of intergenerational programmes in early years settings is the concept of time. In this conceptualisation, time characterises the many changes and histories brought about by its temporal, continuous and infinite nature, visually represented by two circular arrows surrounding the interacting Venn circles and the dotted circle (see Figure 6). Time is core to understanding generational issues, as older adults were children once, and both children and adults will continuously become older in this infinite continuum. This upholds the view of children and older adults as both 'being' and 'becoming' due to the temporal nature of time [52], as has already been discussed in earlier parts of this text. Additionally, in light of cross-sections of time, historical periods, such as the ongoing global pandemic due to the COVID-19 virus and its impact on intergenerational programmes and interactions, can be examined. As an example, this period saw a decrease in the frequency of physical social interactions and an increase in the use of digital technologies to mediate intergenerational interactions [82]. Online services, such as Zoom or FaceTime, offer ways to strengthen social contacts between generations, while still being able to enjoy activities such as reading books or watching movies together [83]. Still, even as technology seemingly mediates intergenerational relations during the time of the pandemic, there are inequalities and disparities exacerbated by access discourses due to variables such as age, ethnicity, race or socioeconomic status that need to be addressed [84]. 


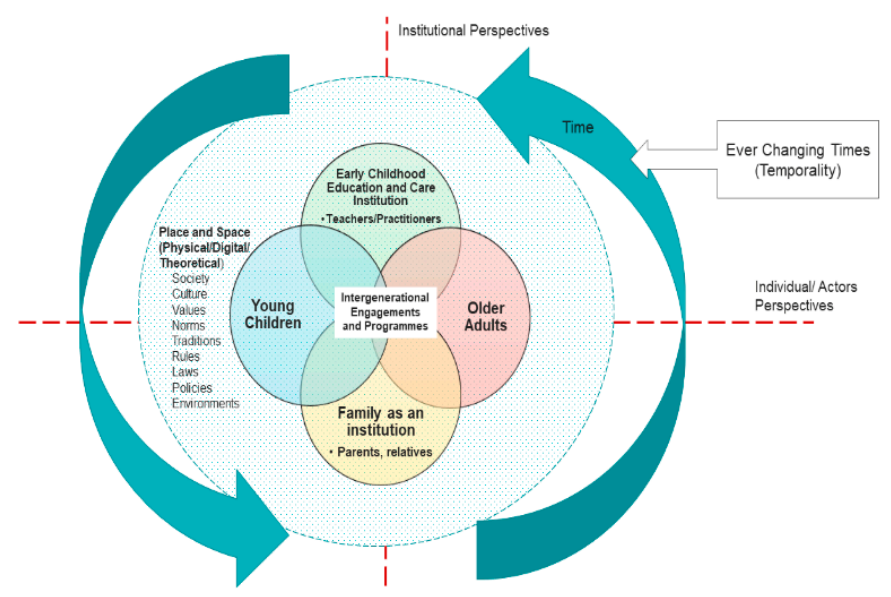

Figure 6. Time.

Vygotsky's [31] concept of the ZPD and critical periods of crises also reflect the temporality of time and the changes it brings. In addition, as humans develop, institutions, activities and programmes also undergo change over time, which has also been emphasised by Hedegaard in her work:

Children develop through participating in everyday activities in societal institutions, but neither society nor its institutions (i.e., families, kindergartens, schools, youth clubs, etc.) are static; rather, they change over time in a dynamic interaction between a person's activities, institutional practice, societal traditions, discourse and material conditions. Several types of institutional practices in a child's social situation influence that child's life and development. At the same time, children's development can be seen as sociocultural tracks through different institutions. Children's development is marked by crises, which are created when change occurs in a child's social situation via biological changes, changes in everyday life activities and relations to other persons or changes in material conditions. [46] (p. 72).

As cultural-historical theory is considered a "living theory and an activist and interventionist theory" [85], in that it is in itself constantly evolving and developing over time, taking time into consideration is essential. It allows an examination of past occurrences in relation to the present and the future, which characterises processes of transition and transformation that could impact conceptualisations, plans, designs and the implementation of intergenerational programmes.

\subsection{Congruent and Conflicting Elemental Overlaps}

The overlaps of the Venn circles (white area) represent the dynamic interactions of each element (see Figure 7). For analysis, the data generated could reveal bigger overlaps, indicating the congruence of elements. Additionally, data could also indicate conflicts, which could be represented by smaller overlaps as an area that could be focused on for future programme designs. As such, in this conceptualisation, this site is a space for both conflicts and opportunities. It is also a space where the following can be visualised, operationalised and analysed: aims, motives and outcomes, tools and mediating artefacts, division of labour and activities and practices within intergenerational programmes. 


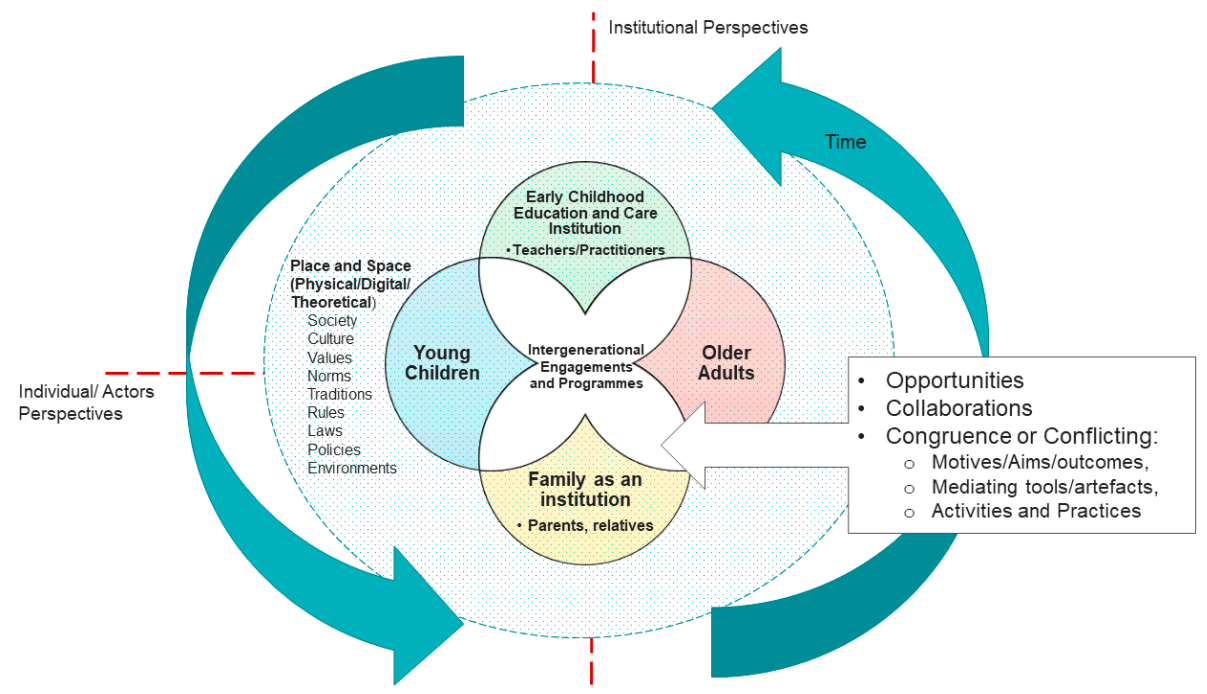

Figure 7. The overlaps: conflicts and opportunities.

While these interactions can represent intergenerational solidarity resulting from the active participation and collaboration of all elements, this space can also represent potential conflicts stemming from the diversity of actors, institutions and their backgrounds (age, ethnicity, context, culture(s), values, etc.). These overlaps and interactions imply that intergenerational interactions may not always yield positive outcomes. These spaces pose an opportunity to elaborate on discourses of intergenerational conflicts that have been identified and problematised over the years, including, but not limited to, concerns about intergenerational transmissions of the cycle of violence [86], economic inequalities observed among age-cohorts due to policies that seem to benefit older generations, and which were not addressed by intergenerational mobility efforts [87-89] and other concerns.

Consequently, these overlaps also represent opportunities for collaborative explorations in pedagogical contexts [29,30], intergenerational dialogues [5] and an arena for cultural formation, or Bildung, in early childhood settings $[13,90]$; these are concepts that may be deemed normative but should rather be considered transformative. Within this framework, intergenerational programmes are to be understood as initiatives to address diversity, participation and inclusion concerns and conflicts that lead towards societies that are relational, intentional and, hence, socially sustainable (see Figure 8).
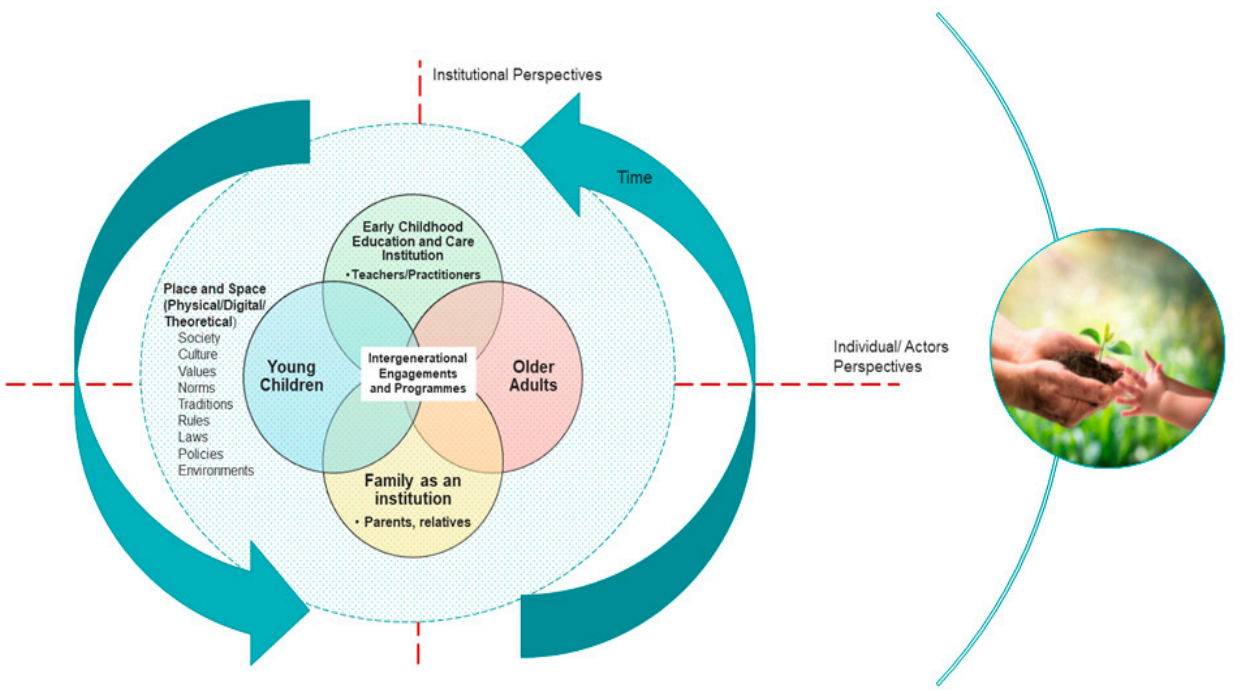

\section{Sustainable} Futures

Figure 8. Intergenerational programmes towards sustainable futures. 


\section{Discussion: Intentional Inclusion of Intergenerational Programmes towards Social Sustainability}

Our conceptual framework highlights an intentional, relational and glocal understanding of intergenerational engagements and programmes leading to a more sustainable future. Intentionality comes from careful consideration of each element that makes up these systematic initiatives. Being able to visualise the interactions and relationships of each element allows us to reflect on how these initiatives could be implemented and further improved in accordance with localised interpretations. As an example of how it can be utilised, we present an example below that reflects data generated from the Philippines during the pandemic lockdown from March to August 2020. Pseudonyms were used to protect the participants' identities.

In the example in Figure 9, we can visualise an intergenerational engagement within a family setting in a province in the Philippines. Data for this example were photos and videos that were sent to us with consent to use for our research. We can see that it is shaped differently because the ECEC institution, locally referred to as preschool, seemingly did not have a role in the intergenerational engagement with a child named Miguel and his maternal grandparents, whom he calls Lolo Jose (grandfather) and Lola Lita (grandmother), during this time. However, Miguel's mother, Mommy Stephanie, and his aunt, Tita Honey, acted as mediators and agents for Miguel and his grandparents' activities to happen by providing the materials they needed for the activities. They reported shared activities using different materials that were somewhat different from what they had been used to performing together prior to the pandemic lockdown, such as farming and chores. Miguel, Lolo Jose and Lola Linda have also reported eating, walking and bike-riding with Mommy Stephanie and Tita Honey. These activities utilise materials and spaces outdoors and in nature; this is reportedly something that is new for them, as their shared activity prior to the pandemic lockdown usually involved watching television with each other. Their experiences revealed an intergenerational engagement that occurs within multigenerational households that are prevalent in the Philippines [91].

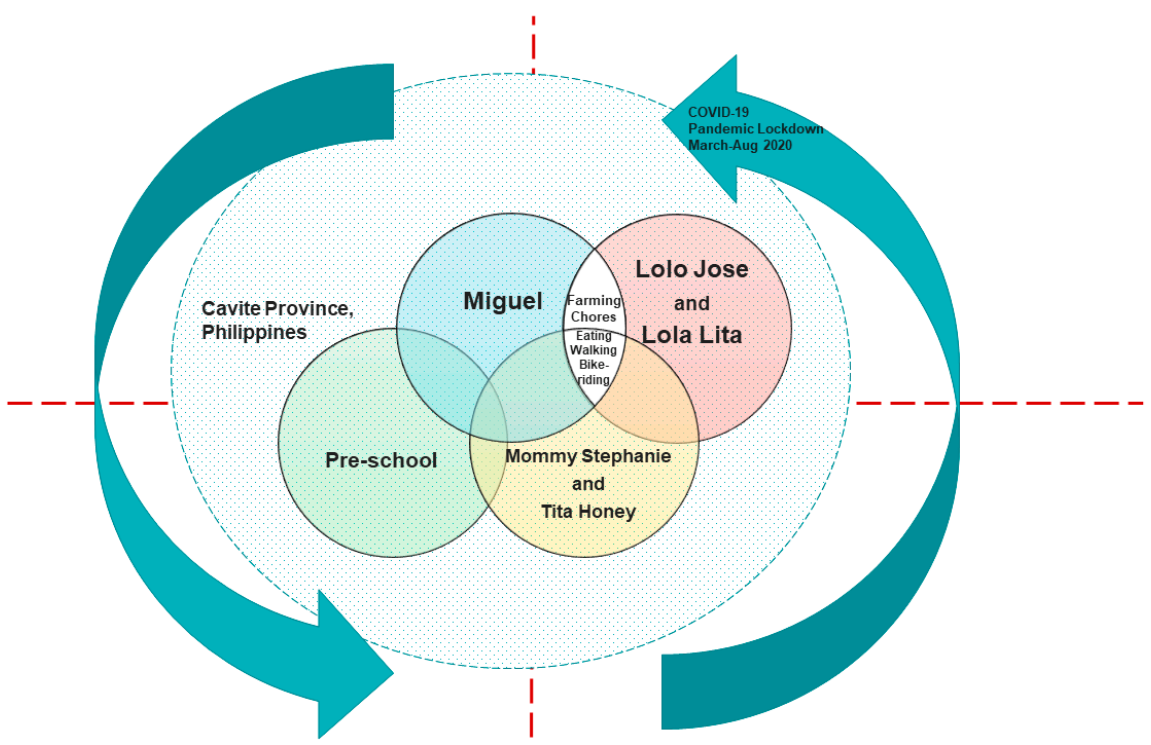

Figure 9. Application example: data generated from the Philippines.

We can go further in the analysis of this example using the data generated from the Philippines by exploring the visual framework before and after the pandemic lockdown to see patterns of similarities and differences in interactions. Maybe there is a need to add more circles to represent other actors or institutions. Maybe there were instances when Miguel's preschool had initiatives that promoted intergenerational engagement between him and his grandparents prior to the pandemic lockdown. If there were and are none, then 
we identified Miguel's preschool as a place for the promotion of intergenerational work. We can ask further questions to investigate and understand this finding, perhaps by looking at the data with indigenous interpretations, as suggested by Oropilla and Guadana [92]. We can also look at several of the elements, such as conflicts in demands and motives in planning the activities, as well as the materials and places used to deepen the analysis of this example.

Through this short example, we have briefly demonstrated how this visual conceptual framework can be used for analysis. The example provided was from the family setting, but we will also be applying this framework to analyse data generated in Norwegian kindergartens. We envision results that will have implications for pedagogical practices that go beyond the institution to community settings. In terms of limitations, as this conceptual framework is still at an exploratory stage, we acknowledge that it could evolve over time as we generate more data. It could also benefit from a systematic review of the literature to scope out other existing visual models of intergenerational engagements and programmes. Additionally, we acknowledge that there may be contexts that might not fit within our framework, as we have limited our scope to the field of ECEC. As such, our framework only currently accounts for the actors and institutions that act within this field.

Ultimately, we hope to highlight an understanding of intergenerational engagements and programmes as a dynamic and complex relational and interactional system of actors and institutions situated in a specific place within a particular time. We point to initiatives that necessitate collaborations and dialogues that lead to shared and common goals of working together to create more intentional and meaningful interactions between young children and older adults. We also point to the need to systematically address cycles of intergenerational conflicts and inequalities that may have been built up and transmitted over the years. This requires shared responsibility and equal involvement of all actors, institutions and societies to address past and current issues of social sustainability that just one generation cannot bear on its own, as well as for the next generations and beyond. As such, this conceptualisation puts the onus of social sustainability on all actors and institutions involved, not just on one generation or sector.

This is in support of Boldermo and Ødegaard [93] in their review of literature on social sustainability, where they found that some research studies paint a picture of children as competent problem-solvers who can take on the issues of social sustainability. They have raised concerns that this might be giving too much credit to children's competence, as it implies too much responsibility on children's shoulders [93]. Their recommendation of a more (inter)generational solution to social sustainability issues is supported by this conceptualisation of intergenerational programmes. This conceptual work is also in support of Davis' [14] work that social sustainability entails having a vision of fairness and justice for all, as well as Vallance, Perkins and Dixon's [20] call to find new ways of living, working and cooperating with each other to strengthen social capital and participation rights.

While the inclusion of intergenerational programmes in early childhood settings might not be new or innovative, there is a need to be more intentional in this inclusion. We know that some intergenerational practices are happening, we know that these are important, and yet we are not talking about them and, sometimes, they are not planned intentionally. This is a paradox that we must examine and address. In this paper, we argue that we must talk about intergenerational solidarity on all levels, that we must include ECEC settings and that it must be deliberate and by design. ECEC is a sector that plays an important role in achieving sustainable goals [14] and contributing to building sustainable societies [15]. As such, we must contribute to the identified space for more intergenerational initiatives between young children and older adults in this field [17] as a response to the call for reimagining early childhood education for social sustainability in the future.

Further, this conceptualisation supports UN General Assembly resolution 73/144 [94] that explicitly states that UN member states are encouraged to invest in inclusive, family oriented policies and programmes, including early childhood development and education towards advancing social integration and intergenerational solidarity to support the 
implementation of the 2030 Sustainable Agenda. Intergenerational solidarity is needed to achieve several UN Sustainable Development Goals, including but not limited to the following-SDG 1 No Poverty, SDG 2 Zero Hunger, SDG 3 Good Health and Well-Being, SDG 4 Quality Education and SDG 16 Peace, Justice and Strong Institutions [94].

\section{Conclusions}

This concept paper proposes a conceptual framework for understanding intergenerational programmes as intentional initiatives that involve the collaboration of several actors and elements that can contribute to the aims of social sustainability. This conceptualisation creates space for renewed understanding and greater awareness of intergenerational engagements and programmes, as well as the elements involved in making these initiatives happen in ECEC institutions. By thinking of each element as being in constant interaction with each other, we highlight the dynamic and relational nature of these engagements, which need to be understood with both global and local knowledge. This promotes intentional consideration and planning to create more possibilities for intergenerational collaborations, albeit with possible conflicts and challenges. Additionally, this frame promotes a transformative view of having more intergenerational opportunities by design and not by chance, as it helps us think of ways to have age-inclusive societies and programmes with intentional designs, where different actors and institutions can participate. In doing so, we also address underlying conflicts, disparities and inequalities that hinder collaborations between actors and prevent intergenerational initiatives from happening.

Now that space for the inclusion of intergenerational programmes in early childhood settings has been identified and articulated, the way forward is to make this space bigger. This strengthens the call for reimagining the future we want. We want a future of togetherness, of conversations, of collaborations, of broader understandings and of shared knowledge and experiences, despite conflicts and challenges. We want spaces and places where different generations can both belong and prosper. We want these initiatives to be deliberate, intentional and by design. In line with The Lancet report discussing a future for the world's children [95], we can continue to think of ways to promote intergenerational solidarity, not just through translation into play activities, pedagogical practices and programmes, but also through space, materials and infrastructure designs. In this way, we are truly reimagining sustainable futures for children, their families, the elderly and communities, which is crucial as the world continues to manifest changes that we must be prepared for.

Author Contributions: Conceptualisation: C.T.O. and E.E.Ø., data curation: C.T.O. formal analysis: C.T.O. and E.E.Ø. funding acquisition: E.E.Ø. and C.T.O. methodology: C.T.O. project administration: C.T.O. resources: C.T.O. and E.E.Ø. software—supervision: E.E.Ø. validation: C.T.O. and E.E.Ø. visualisation-C.T.O. writing—original draft preparation: C.T.O. writing—review and editing: C.T.O. and E.E.Ø. All authors have read and agreed to the published version of the manuscript.

Funding: This research was funded by the Norwegian Research Council, connected with the KINDknow Centre (Kindergarten Knowledge Centre for Systemic Research on Diversity and Sustainable Futures), Western Norway University of Applied Sciences, with grant number 275575.

Institutional Review Board Statement: Since empirical data constitute examples in this conceptual paper, we declare that these data were collected according to the guidelines of the Declaration of Helsinki, and their use is approved by the Norwegian Centre for Research Data (NSD) on 12 May 2019, with reference number 953897, connected with the research project titled Stories of Intergenerational Experiences: The Voices of Younger Children and Older Adults.

Informed Consent Statement: Informed consent was obtained from all participants in the study, parents gave consent on the behalf of their child.

Acknowledgments: We acknowledge the valuable feedback on the draft from colleagues in the KINDknow Centre, Høgskulen på Vestlandet and Conceptual Playlab at Monash University. We acknowledge the inspiration from Professor Mariane Hedegaard's modelling work. We would also like to thank Jean Guadana for her help throughout the review process and in editing the figures. 
Conflicts of Interest: The authors declare no conflict of interest.

\section{References}

1. Barranti, C.C. The Grandparent/Grandchild Relationship: Family Resource in an Era of Voluntary Bonds. Fam. Relat. 1985, 34, 343-352. [CrossRef]

2. Bernal, J.; de la Fuente Anuncibay, R. Intergenerational Grandparent/Grandchild Relations: The Socioeducational Role of Grandparents. Educ. Gerontol. 2007, 34, 67-88. [CrossRef]

3. Agate, J.R.; Agate, S.T.; Liechty, T.; Cochran, L.J. 'Roots and Wings': An Exploration of Intergenerational Play: Research. J. Intergenerational Relatsh. 2018, 16, 395-421. [CrossRef]

4. Monk, H. Play in Three-Generational Families: A Tapestry of Children's Cultural Development. In Proceedings of the Diversities in Early Childhood Education Conference, Strausbourg, France, 26-29 August 2009.

5. Monk, H. Intergenerational Family Dialogues: A Cultural Historical Tool Involving Family Members as Co-Researchers Working with Visual Data. In Visual Methodologies and Digital Tools for Researching with Young Children; Springer: Berlin, Germany, 2014; pp. 73-88. [CrossRef]

6. TOY Consortium. Reweaving the Tapestry of the Generations: An Intergenerational Learning Tour through Europe; TOY Consortium: Leiden, The Netherlands, 2013; Available online: http:/ / www.toyproject.net/wp-content/uploads/2016/01/Summary-English. pdf (accessed on 17 November 2020).

7. Rye, J.F. Leaving the Countryside. Acta Sociol. 2006, 49, 47-65. [CrossRef]

8. UN Department of Economic and Social Affairs. World Social Report 2020: Inequality in a Rapidly Changing World. United Nations. 2020. Available online: https://www.un.org/development/desa/dspd/wp-content/uploads/sites/22/2020/02 /World-Social-Report2020-FullReport.pdf (accessed on 16 January 2021).

9. Newman, S. History and Current Status of the Intergenerational Field; Generations Together Publications, Pittsburgh Univ Center for Social and Urban Research: Pittsburgh, PA, USA, 1995.

10. Hagestad, G.O. The Book-Ends: Emerging Perspectives on Children and Old People; Edward Elgar Publishing: Northampton, UK, 2008.

11. Williams, C. The Sandwich Generation. Elder Care 2004, 712, 2. [CrossRef]

12. Vlachantoni, A.; Evandrou, M.; Falkingham, J.; Gomez-Leon, M. Caught in the Middle in Mid-Life: Provision of Care across Multiple Generations. Ageing Soc. 2020, 40, 1490-1510. [CrossRef]

13. Ødegaard, E.E.; Hedegaard, M. Introduction to Children's Exploration and Cultural Formation. In Children's Exploration and Cultural Formation; Springer: Cham, Switzerland, 2020; pp. 1-10. [CrossRef]

14. Davis, J. Examining Early Childhood Education through the Lens of Education for Sustainability. In Research in Early Childhood Education for Sustainability: International Perspectives and Provocations; Routledge: London, UK, 2014; pp. 21-30.

15. Samuelsson, I.P.; Kaga, Y. The Contribution of Early Childhood Education to a Sustainable Society; Unesco Paris: Paris, France, 2008.

16. Norwegian Directorate of Education and Training. Framework Plan for Kindergartens: Contents and Tasks. Norway. 2017. Available online: https:/ / www.udir.no/globalassets / filer/barnehage/rammeplan/framework-plan-for-kindergartens2-2017. pdf (accessed on 17 November 2020).

17. Oropilla, C.T. Spaces for Transitions in Intergenerational Childhood Experiences. In Childhood Cultures in Transformation; Ødegaard, E.E., Borgen, J.S., Eds.; Brill I Sense: Leiden, The Netherlands, 2021; pp. 74-120. [CrossRef]

18. Siraj-Blatchford, J.; Pramling-Samuelsson, I. Education for Sustainable Development in Early Childhood Care and Education: An Introduction. In International Research on Education for Sustainable Development in Early Childhood; Siraj-Blatchford, J., Mogharreban, C., Park, E., Eds.; Springer International Publishing: Cham, Switzerland, 2016; pp. 1-15.

19. Boldermo, S. Education for Social Sustainability. Meaning Making of Belonging in Diverse Early Childhood Settings. Ph.D. Thesis, PhD Programme in Humanities and Social Sciences, The Arctic University of Norway, Tromsø, Norway, 2020.

20. Vallance, S.; Perkins, H.C.; Dixon, J.E. “What Is Social Sustainability? A Clarification of Concepts”. Geoforum 2011, 42, 342-348. [CrossRef]

21. TOY Consortium. Intergenerational Learning Involving Young Children and Older People; The TOY Project: Leiden, The Netherlands, 2013; Available online: http://www.toyproject.net/wp-content/uploads/2016/01/Summary-English.pdf (accessed on 17 November 2020).

22. Cartmel, J.; Radford, K.; Dawson, C.; Fitzgerald, A.; Vecchio, N. Developing an Evidenced Based Intergenerational Pedagogy in Australia. J. Intergenerational Relatsh. 2018, 16, 64-85. [CrossRef]

23. Alanen, L. Generational Order. In The Palgrave Handbook of Childhood Studies; Springer: Berlin, Germany, 2009 ; pp. 159-174.

24. Hedegaard, M.; Fleer, M. Studying Children: A Cultural-Historical Approach; Open University Press: Maidenhead, UK; New York, NY, USA, 2008.

25. Hedegaard, M. Children's Perspectives and Institutional Practices as Keys in a Wholeness Approach to Children's Social Situations of Development. In Cultural-Historical Approaches to Studying Learning and Development: Societal, Institutional and Personal Perspectives; Edwards, A., Fleer, M., Bøttcher, L., Eds.; Springer: Singapore, 2019; pp. 23-41.

26. Bronfenbrenner, U. Toward an Experimental Ecology of Human Development. Am. Psychol. 1977, 32, 513. [CrossRef]

27. Bronfenbrenner, U.; Morris, P.A. The Bioecological Model of Human Development. Handb. Child. Psychol. 2007, 1. [CrossRef]

28. Rogoff, B. The Cultural Nature of Human Development; Oxford University Press: Cary, NC, USA, 2003. 
29. Ødegaard, E.E. Dialogical Engagement and the Co-Creation of Cultures of Exploration. In Children's Exploration and Cultural Formation; Hedegaard, M., Ødegaard, E.E., Eds.; Springer International Publishing: Cham, Switzerland, 2020 ; pp. 83-104. [CrossRef]

30. Ødegaard, E.E. Reimagining "Collaborative Exploration"-A Signature Pedagogy for Sustainability in Early Childhood Education and Care. Sustainability 2021, 13, 5139. [CrossRef]

31. Vygotsky, L.S. The Collected Works of L. S. Vygotsky. Volume 5. Child. Psychology; Plenum Press: New York, NY, USA, 1998.

32. Bruner, J. Prologue to the English Edition. In The Collected Works of Ls Vygotsky; Rieber, R.W., Carton, A.S., Eds.; Plenum Press: New York, NY, USA, 1987; pp. 1-16.

33. Bakhtin, M.M.; Holquist, M.; Emerson, C. The Dialogic Imagination: Four Essays; University of Texas Press: Austin, TX, USA, 1981; Volume 1.

34. Vygotsky, L.S. The Development of Higher Forms of Attention in Childhood. In The Concept of Activity in Soviet Psychology; Wertsch, J.V., Ed.; M. E. Sharpe: Armonk, NY, USA, 1981.

35. Minick, N. The Development of Vygotsky's Thought: An Introduction. In The Collected Works of Ls Vygotsky; Rieber, R.W., Carton, A.S., Eds.; Plenum Press: New York, NY, USA, 1987; pp. 17-36.

36. Vygotsky, L.S. The Problem of Age, Transcribed by Andy Blunden. Collect. Works LS Vygotsky 1998, 5, 187-205.

37. Rogoff, B.; Sellers, M.J.; Pirrotta, S.; Fox, N.; White, S.H. Age of Assignment of Roles and Responsibilities to Children. Hum. Dev. 1975, 18, 353-369. [CrossRef]

38. Rogoff, B.; Najafi, B.; Mejía-Arauz, R. Constellations of Cultural Practices across Generations: Indigenous American Heritage and Learning by Observing and Pitching In. Hum. Dev. 2014, 57, 82-95. [CrossRef]

39. Coppens, A.D.; Silva, K.G.; Ruvalcaba, O.; Alcalá, L.; López, A.; Rogoff, B. Learning by Observing and Pitching In: Benefits and Processes of Expanding Repertoires. Hum. Dev. 2014, 57, 150-161. [CrossRef]

40. Vygotsky, L.S. Socio-Cultural Theory. Mind Soc. 1978, 6, 52-58.

41. Wartofsky, M. Artifacts, Representations and Social Practice: Essays for Marx Wartofsky; Gould, C.C., Cohen, R.S., Eds.; Boston Studies in the Philosophy of Science; Kluwer Academic Publishers: Dordrecht, The Netherlands, 1994.

42. Wartofsky, M. Models: Representation and the Scientific Understanding; Boston Studies in the Philosophy of Science; Springer: Dordrecht, The Netherlands, 1979.

43. Cole, M. Re-Covering the Idea of a Tertiary Artifact. In Cultural-Historical Approaches to Studying Learning and Development-Societal, Institutional and Personal Perspectives; Fleer, M., Böttcher, L., Eds.; Springer Nature: Basingstoke, UK, 2019; pp. 303-321.

44. Ødegaard, E.E. A Pedagogy of Collaborative Exploration-A Case Study of the Transition from a Monocultural Entity in National Celebration Rituals to a Multilayered Informed Pedagogical Practice. In Qualitative Studies of Exploration in Childhood Transitions: Cultures of Play and Learning; Fleer, M., Hedegaard, M., Ødegaard, E.E., Sørensen, H.V., Eds.; Bloomsbury: London, UK, in print.

45. Hedegaard, M. Children's Perspectives and Institutional Practices as Keys in a Wholeness Approach to Children's Social Situations of Development. Learn. Cult. Soc. Interact. 2020, 26, 100229. [CrossRef]

46. Hedegaard, M. Children's Development from a Cultural-Historical Approach: Children's Activity in Everyday Local Settings as Foundation for Their Development. Mind Cult. Act. 2009, 16, 64-82. [CrossRef]

47. Hedegaard, M.; Aronsson, K.; Højholt, C.; Ulvik, O.S. Children, Childhood, and Everyday Life: Children's Perspectives; IAP: Charlotte, NC, USA, 2018.

48. Edwards, A.; Fleer, M.; Bøttcher, L. Cultural-Historical Approaches to Studying Learning and Development: Societal, Institutional and Personal Perspectives; Springer: Singapore, 2019; pp. 1-20. [CrossRef]

49. United Nations. Convention on the Rights of the Child. 1989. Available online: http://wunrn.org/reference/pdf/Convention_ Rights_Child.PDF (accessed on 27 March 2021).

50. Grindheim, L.T.; Borgen, J.S.; Ødegaard, E.E. Chapter 2 in the Best Interests of the Child: From the Century of the Child to the Century of Sustainability. In Childhood Cultures in Transformation; Eriksen, E., Ødegaard, J.S.B., Eds.; Brill ISense: Leiden, The Netherlands, 2021; pp. 13-36. [CrossRef]

51. Tatlow-Golden, M.; Montgomery, H. Childhood Studies and Child Psychology: Disciplines in Dialogue? Child. Soc. 2021, 35, 3-17. [CrossRef]

52. Uprichard, E. Children as 'Being and Becomings': Children, Childhood and Temporality. Child. Soc. 2008, 22, 303-313. [CrossRef]

53. Lee, N. Childhood and Society: Growing Up in an Age of Uncertainty; Issues in Society; Open University Press: Buckingham, UK, 2001.

54. James, A.; Jenks, C.; Prout, A. Theorizing Childhood; Polity Press: Cambridge, UK, 1998.

55. Qvortrup, J. The Waiting Child; Sage Publications Sage CA: Thousand Oaks, CA, USA, 2004.

56. Corsaro, W.A. The Sociology of Childhood. In Sociology for a New Century, 4th ed.; Sage: Los Angeles, CA, USA, 2015.

57. Ødegaard, E.E. 'Glocality' in Play: Efforts and Dilemmas in Changing the Model of the Teacher for the Norwegian National Framework for Kindergartens. Policy Futures Educ. 2015, 14, 42-59. [CrossRef]

58. Walker, A.; Gemeinschaften, G.B.E. Age and Attitudes: Main Results from a Eurobarometer Survey. Commission of the European Communities. 1993. Available online: https://ec.europa.eu/public_opinion/archives/ebs/ebs_069_en.pdf (accessed on 27 March 2019).

59. United Nations Committee on Economic, Social and Cultural Rights. The Economic, Social and Cultural Rights of Older Persons. Geneva. 1995. Available online: https:/ / www.refworld.org/pdfid/4538838f11.pdf (accessed on 27 March 2019).

60. Falconer, M.; O'Neill, D. Out with “the Old," Elderly, and Aged. BMJ 2007, 334, 316. [CrossRef] 
61. Newman, S.; Ward, C.R.; Smith, T.B. Intergenerational Programs: Past, Present, and Future; Taylor \& Francis US: New York, USA, 1997. [CrossRef]

62. Roos, N.P.; Havens, B.; Black, C. Living Longer but Doing Worse: Assessing Health Status in Elderly Persons at Two Points in Time in Manitoba, Canada, 1971 and 1983. Soc. Sci. Med. 1993, 36, 273-282. [CrossRef]

63. Laroche, M.L.; Charmes, J.P.; Bouthier, F.; Merle, L. Inappropriate Medications in the Elderly. Clin. Pharmacol. Ther. 2009, 85, 94-97. [CrossRef] [PubMed]

64. Kaplan, M.; Sanchez, M.; Hoffman, J. Intergenerational Pathways to a Sustainable Society; Springer International Publishing: Cham, Switzerland, 2017.

65. Cornwell, E.Y.; Waite, L.J. Social Disconnectedness, Perceived Isolation, and Health among Older Adults. J. Health Soc. Behav. 2009, 50, 31-48. [CrossRef] [PubMed]

66. EMIL Network. What Is Intergenerational Learning? Available online: http://www.emil-network.eu/what-is-intergenerationallearning/ (accessed on 27 March 2019).

67. Beth Johnson Foundation. A Guide to Intergenerational Practice. 2011. Available online: http:/ /www.ageingwellinwales.com/ Libraries/Documents/Guide-to-Intergenerational-Practice.pdf (accessed on 27 March 2019).

68. Airey, T.; Smart, T. Holding Hands Intergenerational Programs Connecting Generations. 2015. Available online: http://www. issinstitute.org.au/wp-content/media/.../ReportAirey-Smart-Final-LowRes.pdf (accessed on 27 March 2019).

69. Eurochild. How Young Children, Adults and Communities Benefit from Intergenerational Activities. 2016. Available online: http:/ / www.eurochild.org/news/news-details/article/how-young-children-adults-and-communities-benefit-fromintergenerational-activities /?tx_news_pi1\%5Bcontroller\%5D=News\&tx_news_pi1\%5Baction\%5D=detail\&cHash=4300947b9 b4d81ea7d432564dc05c94f (accessed on 26 March 2019).

70. Norwegian Ministry of Health and Care Services. Public Health Report-A Good Life in a Safe Society. Norwegian Ministry of Health and Care Services. Norway: Solberg Government. 2020. Available online: https://www.regjeringen.no/no/dokumenter/ meld.-st.-19-20182019/id2639770/ (accessed on 5 February 2021).

71. Hedegaard, M. Analyzing Children's Learning and Development in Everyday Settings from a Cultural-Historical Wholeness Approach. Mind Cult. Act. 2012, 19, 127-138. [CrossRef]

72. James, A.; Prout, A. Constructing and Reconstructing Childhood: Contemporary Issues in the Sociological Study of Childhood, 3rd ed.; Routledge Education Classic Edition; Routledge: London, UK, 2015.

73. James, A.; Prout, A. Re-Presenting Childhood: Time and Transition in the Study of Childhood. In Constructing and Reconstructing Childhood: Contemporary Issues in the Sociological Study of Childhood; Routledge: London, UK, 1997; pp. $230-250$.

74. Alanen, L.; Mayall, B. Conceptualizing Child-Adult Relations; Routledge: London, UK, 2001.

75. Mayall, B. Towards a Sociology for Childhood: Thinking from Children's Lives; Open University Press: Buckingham, UK, 2002.

76. Garvis, S.; Lemon, N.; Ødegaard, E.E. Beyond Observations: Narratives and Young Children; Sense Publishers: Rotterdam, The Netherlands, 2015.

77. Alanen, L. Childhood and Intergenerationality: Toward an Intergenerational Perspective on Child Well-Being. In Handbook of Child. Well-Being; Ben-Arieh, A., Casas, F., Frønes, I., Korbin, J., Eds.; Springer: Dordrecht, The Netherlands, 2014; pp. 131-160. Available online: https:/ / doi-org.galanga.hvl.no/10.1007/978-90-481-9063-8_5 (accessed on 27 March 2020).

78. Harrison, S.; Dourish, P. Re-Place-Ing Space: The Roles of Place and Space in Collaborative Systems. In Proceedings of the 1996 ACM Conference on Computer Supported Cooperative Work; Association for Computing Machinery: New York, NY, USA, 1996; pp. 67-76. Available online: https:/ /dl.acm.org/doi/pdf/10.1145/240080.240193?casa_token=Ceb7YhPn9lcAAAAA:alKIAh4 Y5XNVJTfiSs1zLaI4TST-G3HEq6vRFnOPS0zopHhvXFrw7tVUUd8iovHgktnmAOgcVAhrHQ (accessed on 14 April 2021).

79. Smahel, D.; Machackova, H.; Mascheroni, G.; Dedkova, L.; Staksrud, E.; Ólafsson, K.; Livingstone, S.; Hasebrink, U. EU Kids Online 2020: Survey Results from 19 Countries. 2020. Available online: https:/ / www.lse.ac.uk/media-and-communications / assets / documents/research/eu-kids-online/reports/EU-Kids-Online-2020-March2020.pdf (accessed on 27 March 2021).

80. Holloway, D.; Green, L.; Livingstone, S. Zero to Eight: Young Children and Their Internet Use. 2013. Available online: http:/ / eprints.lse.ac.uk/52630/1/Zero_to_eight.pdf (accessed on 27 March 2019).

81. Lansdown, G. Every Child's Right to Be Heard: A Resource Guide on the Un Committee on the Rights of the Child General Comment No. 12; Save the Children/United Nations Children's Fund: London, UK, 2011.

82. Arpino, B.; Pasqualini, M.; Bordone, V. Physically Distant but Socially Close? Changes in Intergenerational Non-Physical Contacts During the Covid-19 Pandemic among Older People in France, Italy and Spain. Eur. J. Ageing 2020. [CrossRef]

83. Diehl, M.; Levy, B.R.; Wahl, H.W.; Tesch-Romer, C.; Ayalon, L.; Rothermund, K.; Neupert, S.D.; Chasteen, A. Aging in Times of the Covid-19 Pandemic: Avoiding Ageism and Fostering Intergenerational Solidarity. J. Gerontol. B Psychol. Sci. Soc. Sci. 2020, 76, 1-4. [CrossRef]

84. Gilligan, M.; Suitor, J.J.; Rurka, M.; Silverstein, M. Multigenerational Social Support in the Face of the Covid-19 Pandemic. J. Family Theory Rev. 2020, 12, 431-447. [CrossRef]

85. Ploettner, J.; Tresseras, E. An Interview with Yrjö Engeström and Annalisa Sannino on Activity Theory. Bellaterra J. Teach. Learn. Lang. Lit. 2016, 9, 87. [CrossRef]

86. Widom, C.S.; Wilson, H.W. Intergenerational Transmission of Violence. In Violence and Mental Health; Lindert, J., Levav, I., Eds.; Springer: Dordrecht, The Netherlands, 2015; pp. 27-45. [CrossRef] 
87. Marasco, A.; Romano, A. Deterministic Modeling in Scenario Forecasting: Estimating the Effects of Two Public Policies on Intergenerational Conflict. Qual. Quant. 2015, 52, 2345-2371. [CrossRef]

88. Beckfield, J. Rising Inequality Is Not Balanced by Intergenerational Mobility. Proc. Natl. Acad. Sci. USA 2020, 117, 23-25. [CrossRef] [PubMed]

89. DiPrete, T.A. The Impact of Inequality on Intergenerational Mobility. Annu. Rev. Sociol. 2020, 46, 379-398. [CrossRef]

90. Ødegaard, E.E.; White, E.J. Bildung: Potential and Promise in Early Childhood Education. In Encyclopedia of Educational Philosophy and Theory; Springer: Singapore, 2018; pp. 73-79. [CrossRef]

91. Philippine Statistics Authority. 2015 Facts on Senior Citizens. Republic of the Philippines. 2015. Available online: https://psa.gov ph/system/files/2015\%20Fact\%20Sheets\%20on\%20Senior\%20Citizen_pop.pdf?width=950\&height=700\&iframe=true (accessed on 7 July 2020).

92. Oropilla, C.T.; Guadana, J.C. Intergenerational Learning and Sikolohiyang Pilipino: Perspectives from the Philippines. Nord. J. Comp. Int. Educ.. in review.

93. Boldermo, S.; Ødegaard, E.E. What About the Migrant Children? The State-of-the-Art in Research Claiming Social Sustainability. Sustainability 2019, 11, 459. [CrossRef]

94. United Nations. Resolution Adopted by the General Assembly on 17 December 2018: Follow-up to the Twentieth Anniversary of the International Year of the Family and Beyond. 2019. Available online: http:/ / www.familyperspective.org/undocs / ARES731 442018.pdf (accessed on 7 July 2020).

95. Clark, H.; Coll-Seck, A.M.; Banerjee, A.; Peterson, S.; Dalglish, S.L.; Ameratunga, S.; Balabanova, D.; Bhan, M.K.; Bhutta, Z.A.; Borrazzo, J.; et al. A future for the world's children? A WHO-UNICEF-Lancet Commission. Lancet 2020, 395, 605-658. [CrossRef] 